\title{
The Art and Science of Fluid Mechanics As a General Education Course
}

\section{Dr. Azar Eslam Panah, Pennsylvania State University, Berks}

Dr. Eslam-Panah is an Assistant Professor of Mechanical Engineering at the Penn State University at Berks and her specialty is in thermodynamics and fluid mechanics. Her research interests include unsteady aerodynamics of biologically-inspired air and underwater vehicles, fluid dynamics in human bodies (e.g. cardiovascular and respiratory), and engineering education. She uses various experimental techniques such as Particle Image Velocimetry (PIV) and dye flow visualization and try to persuade her undergraduate students to investigate interesting questions in fluid mechanics with her.

\section{Heidi Reuter}




\title{
The Art and Science of Fluid Mechanics as a General Education Course
}

\begin{abstract}
A new experimental course on flow visualization (PHOTO 321N) is offered to undergraduate students as a General Education (GenEd) course at Penn State University. This course is intended to make integration between two knowledge domains: Art and Science of Fluid Mechanics. The course is not math oriented and is designed for the students with minimal to no background in photography or physics of fluid mechanics. Students explore a variety of aesthetic issues in the form of practical and creative assignments. The course consists of lectures on photography skills, fluid physics, visualization techniques, critique sessions, and a guest lecture. Assignments consist of images paired with written technical reports, and selfreflection sessions to learn "effective communication" skills. Other course objectives evaluated through students' assignments and projects are "creative thinking" and "integrative thinking". Some samples of student works are presented. This course proved to be very successful in attracting all students (male and female) in both engineering and non-engineering majors.
\end{abstract}

\section{Introduction}

There has been a great interest in bridging the science and art in recent. Three organizations that promote integration of art and science are Art \& Science Collaborations, Inc. (ASCI), International Society of the Arts, Mathematics, and Architecture (ISAMA) and International Society for the Arts, Sciences, and Technology (ISAST). In academia, educators are always experimenting new methods to increase students engagement in the course materials. One such effort in fluid mechanics is a course on the physics and art of flow visualization, by Dr. Jean Hertzberg (at the University of Colorado, Boulder) [1-3]. The course is offered since 2003 as a technical elective to the engineering students and as studio credit to the fine arts students and has shown to be very effective. Gary Settles (at Pennsylvania State University) is a Distinguished Professor Emeritus in mechanical engineering and a self-taught painter whose paintings take on the subject of fluid dynamics. He always encouraged others to embark on integration of fluid dynamics and art. [4,5] Said Shakerin (at the University of the Pacific) has used water fountains with special effects as a medium to inspire his students to use fluid dynamics in creating artistic projects. [6-8] Such water fountains, which were made possible by advances in computer control technology, have become popular in the last 25 years in theme parks, resorts, and city centers. 
In contrast to such efforts, ABET precludes engineering students from applying any fine art studio course towards their degree except as GenEd courses. It is concerned that by excluding such courses, students think that artistic creativity is not valued in engineering, which is absolutely not the case is engineering designs. The net result is that creative students are likely discouraged from engineering, resulting in reduced intellectual diversity in our students, and possibly in reduced gender and cultural diversity as well. However, most Universities today recognize the importance of a comprehensive education that includes interdisciplinary studies. Recently, there has been a new movement to turn STEM (science, technology, engineering and math) into STEAM, with the A contributed by Art. [9] The authors would like to showcase this work in the national STEM to STEAM dialogue as an example of how this movement can develop a successful union of art into the sciences. The first showcase will be at the American Physical Society, Division of Fluid Dynamics, as an education symposia lecture. Another plan is to present this work as a workshop at Lilly Conferences that provides opportunities for the presentation of the scholarship of teaching and learning. With more historical background, this could present the developments within fluid mechanics against the backdrop of scientific development.

In April 2015, the University Faculty Senate (UFS) at Penn State University approved a new Integrative Studies requirement within General Education; implementation details were approved in March of 2016. This requirement applies to students who start at Penn State University during or after the summer of 2018. There are two pathways for students to accomplish this requirement: 6 credits of either inter-domain or linked coursework. Inter-domain courses are courses with 3 credits that, within the one course, address two General Education domains (Natural Sciences (GN), Health and Wellness (GHW), Arts (GA), Humanities (GH), Social and Behavioral Sciences (GS)) with approximately equal attention (in course topics, assignments, or other course components). On the other hand, Linked courses propose at least two courses (total at least 6 credits) and represent two different domains, creating a functional "linkage" for students. Each linked course must contain a purposefully integrated component across all the courses in the "linked set." Such courses have never before been required or had a recognized designation at Penn State University, and therefore the University must have prepared to make these types of courses available to students.

The Office for General Education invited seed grant proposals for the development of courses that would meet the criteria for Integrative Studies courses as defined by University Faculty Senate reports. General Education seed grants were awarded to projects that proposed courses that are expected to have broad student appeal; embrace the intention and goals of the General Education update, specifically around the integrative thinking learning objective; and reflect other General Education learning objectives. Priority was given to proposals that were transferable to a range of University campuses and that engage faculty from different colleges, 
units, or other University structures. Flow Visualization course was a natural fit for this initiative and it received the seed grant award to develop the integrated-domain course on art and science of fluid motion over academic year of 2016-2017. Some other examples of such integrative courses are: Politics of Hip Hop, From Beast Books to Dinosaurs Resurrected, Race in the Humanities and in the Social Sciences, Psychology in the Cinema and the Arts, Scientific Controversies and Public Debate. The proposed Flow Visualization course was inspired by Dr. Jean Hertzberg's course at University of Colorado, Boulder [10] and motivated by a desire to explore the importance of creative aesthetics, of making art, in the education of engineers and scientists. Images contribute significantly to the development, communication, and popularization of science and engineering, and learning how to make good and careful observations is a required skill for both engineers and artists.

The final set of course materials developed by the end of the grant period included: a complete course syllabus including learning outcomes, course content, weekly assignments and other assessments of student learning, reading list, course materials and resources, and sample evaluation criteria including assessments which enable evaluation of integrative thinking and other General Education objectives addressed in the course. A resulting curricular course proposal was submitted through UFS curricular processes and went through consultation procedure. Finally, the course proposal was approved by UFS in April, 2018 and offered to students for the first time in Fall 2018.

\section{Course Objectives and Description}

This course reveals the techniques of making laboratory and everyday fluid flows visible for both scientific and aesthetic purposes. In this course, students explore techniques for the visualization of the physics of fluid flows including seeding with dyes and particles. Students will also gain technical expertise in a range of photographic techniques drawn from the course topics, such as photographing atmospheric clouds. Assignments are student-driven, to individuals and mixed teams of undergrad students from different majors. Students create images using photographic techniques, and document their work in written reports. Questions such as "what makes an image scientific?" and "what makes an image art?" are explored. The consensus was that the answer to the former is easy: any image of fluid flow can be considered science if the conditions of the fluid flow and the image acquisition and production process are known. The answer to the latter was, of course, a matter of personal interpretation. Despite the light treatment of art in the formal lectures, images produced by the students are unarguably artistic (samples can be seen below). There are no prerequisites for this course which is similar to an introductory course on photography, focused on fluid related objects. Students learn the science behind natural phenomena related to fluid flows and learn how to visualize fluid motion. This course needs little Mathematics and Physics background and all the topics are explained during lecture classes understandable for students of all majors with High School knowledge level. 
The main objectives of this course are:

- Integrative Thinking - One important objective of this course is to help students to look at things from a different perspective and become more open to an aesthetic appreciation of, and motivation for, other fields of science and engineering which may lead to life-long learning even if they don't continue in their study of fluids or photography. They will achieve the ability to synthesize knowledge across science and art domains, so students will be able to transfer knowledge within and beyond their current contexts by combining analytical and creative skills to cultivate the relationship between science and art.

- Creative Thinking - This course has the capacity to promote creative thinking by recognition of the beauty of fluid physics that surrounds us each day. Fluid physics are responsible for a wide range of natural beauties and disasters such as floods, tornadoes, and wildfires. Images and videos of such disasters are very popular which could be another relationship between art and science that students can learn from this course. Many fluid physicists are motivated not only by the important scientific goals of their work, but also by a fascination with their subject.

- Effective Communication - Another important objective of this course is to expose students to simple physics of fluids which cannot be accomplished verbally, but only visually. Students will gain the ability to exchange new ideas in visual form to show the beauty of fluid flow. Reports will be required for each assignment and students' work will be evaluated for both artistic and scientific merit. Students are challenged to find the beauty in the interaction between different fluids and documenting the outcome through photography.

\section{Course Structure}

The flow visualization course was offered in Fall 2018 as a GenEd course to all undergraduate students from all majors. It was co-taught by Professors Eslam-Panah and Reuter to a group of mixed engineering and other majors at Penn State Berks. Of 24 students, 6 were engineering students and the rest from psychology, art, science, business, communication, etc. majors. Students could take the course for either General Education Art (GA) or General Education Natural Science (GN) or General Education Integrative Studies (GI) domains, based on students' preferences to meet their GenEd requirements. The class met two times a week, Tuesday and Thursday, each 75 minutes.

At the beginning of semester, there were two lectures on fluid properties (density, viscosity, temperature, pressure, buoyancy, etc.). There were two additional lectures on basic photographic techniques: Shutter Speed, Aperture, ISO, White Balance. This was primarily for the benefit of all students, many of whom had little or no science or photography experience. Emphasis was placed on the quantitative aspects of optics and the interrelationship of spatial and temporal resolution in the measurement of fluid flows. 
Six major topics were selected and for each topic a set of four class times was considered. Each set of four classes was structured as 1) a lecture on the science and visualization techniques of a topic (Tuesday), 2) a photography session (Thursday), 3) edit/submit session to edit the images in Photoshop and write a report (Tuesday), 3) critique session (Thursday). The six selected topics were:

1. dye flow visualization in milk \& dye mixture (Fig. 1),

2. clouds, humidity, dews, and weather prediction (Fig. 2),

3. florescent dye visualization in dark (Fig. 3),

4. particle imaging and smoke visualization (Fig. 4),

5. vortex flows and surface waves (Fig. 5),

6. heat convection and Schlieren technique (Fig. 6).

The lectures on flow visualization techniques and fluid physics of a topic (gas and liquid flows) were carefully introduced to be understandable by ALL students from different background. They included lots of graphics, educational videos, and short in-class quizzes to review the materials. Students were given some scientific articles to read after each topic to receive more indepth appreciation of each topic. Each lecture was followed by a group photography session in a lab setup or outdoor with the actual image acquisition assigned as homework. On the third session of each round, students learned appropriate tools in Photoshop to edit their top images to include in their report and get ready for the submission. The fourth session was critique session by themselves, their peers, or their professors, alternatively. Then, the session was concluded with some remarks on each topic and introducing the next topic.
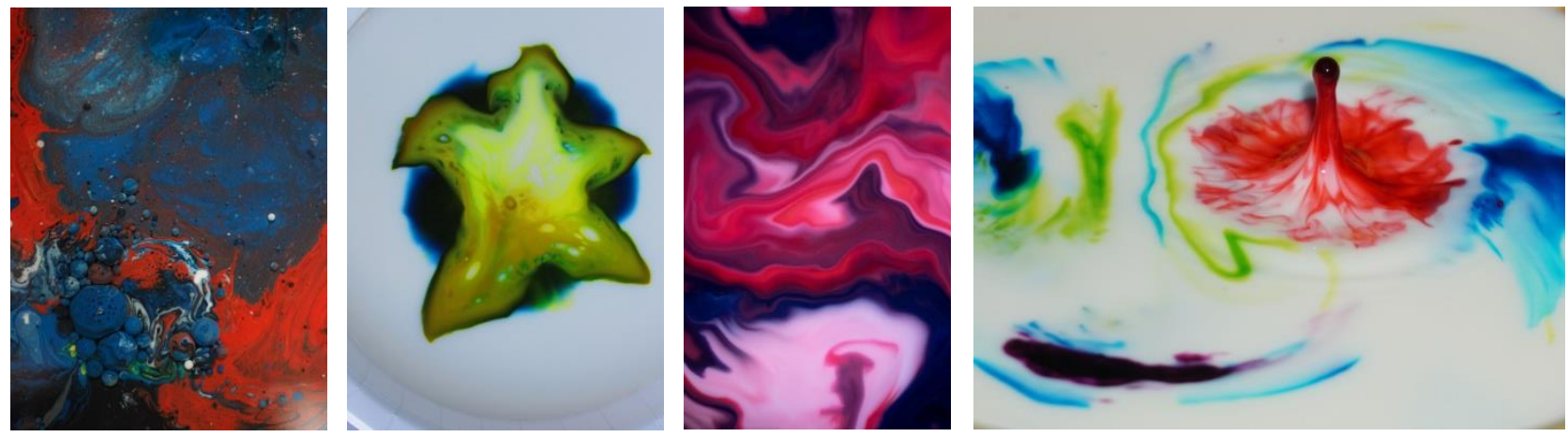

Fig. 1. Assignment 1: milk \& dye mixture 

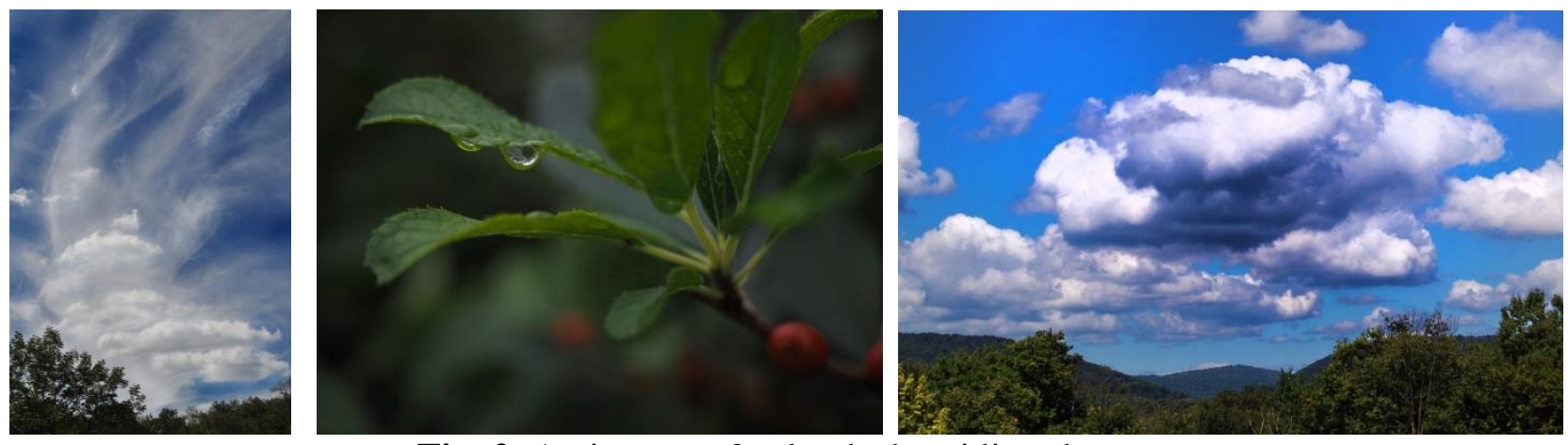

Fig. 2. Assignment 2: clouds, humidity, dews

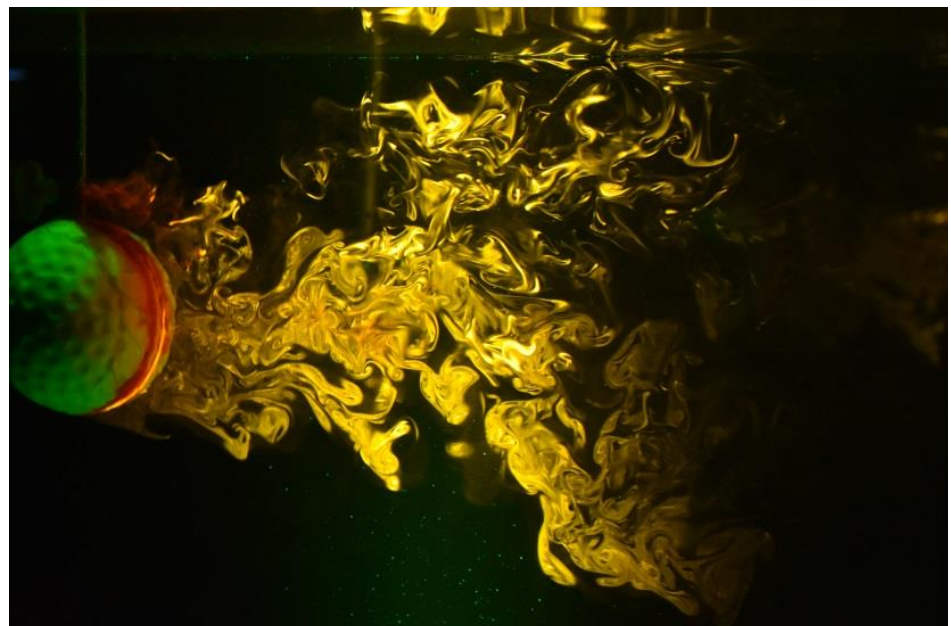

Fig. 3. Assignment 3: florescent dye visualization in dark
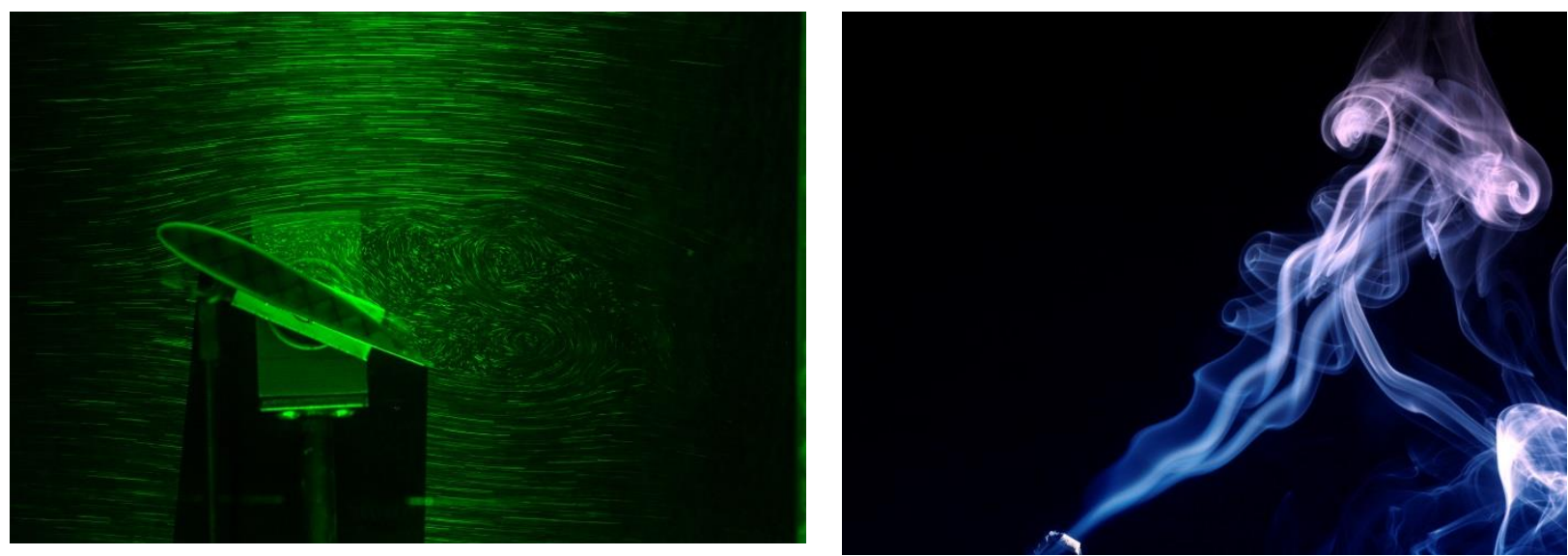

Fig. 4. Assignment 4: particle imaging and smoke visualization 

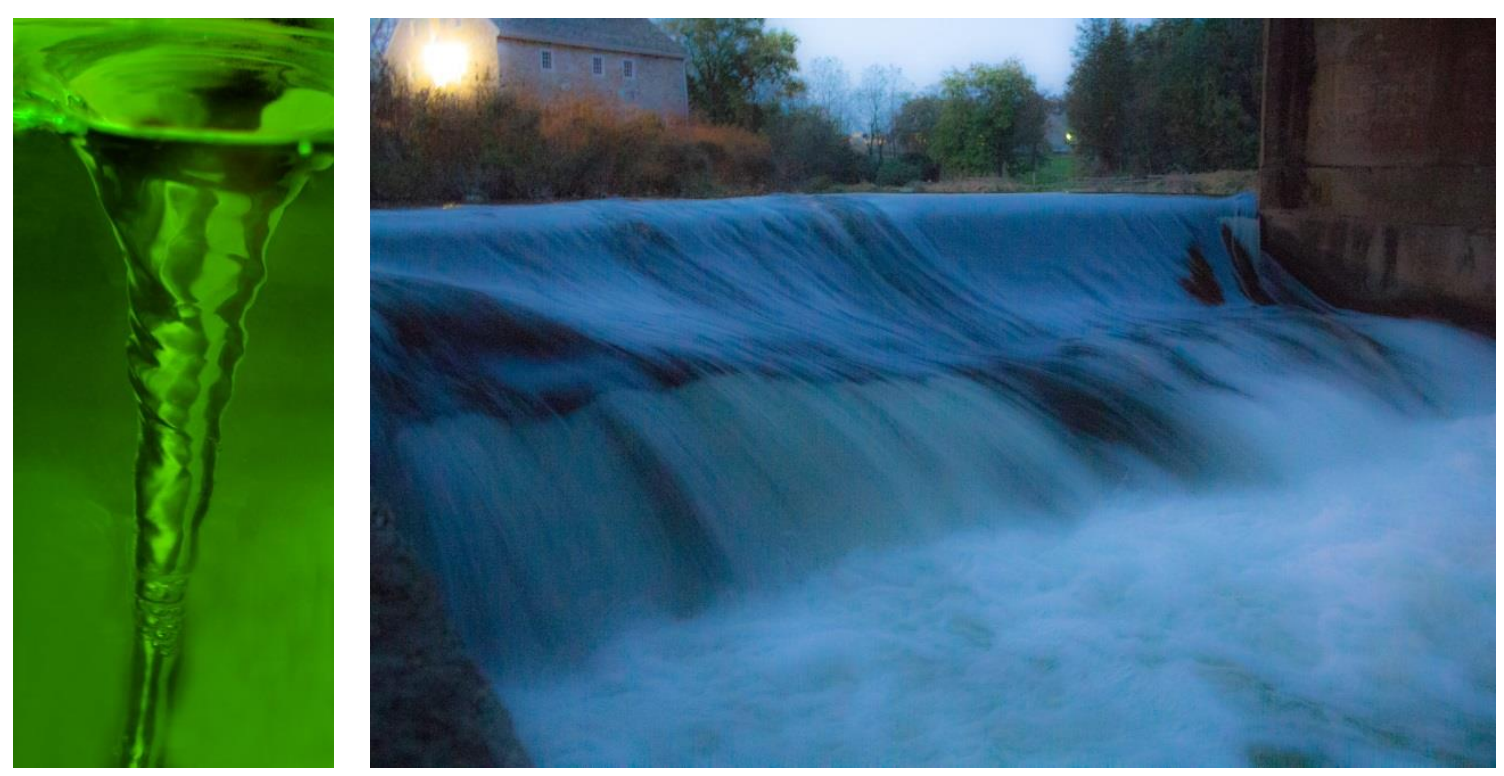

Fig. 5. Assignment 5: vortex flows and surface waves
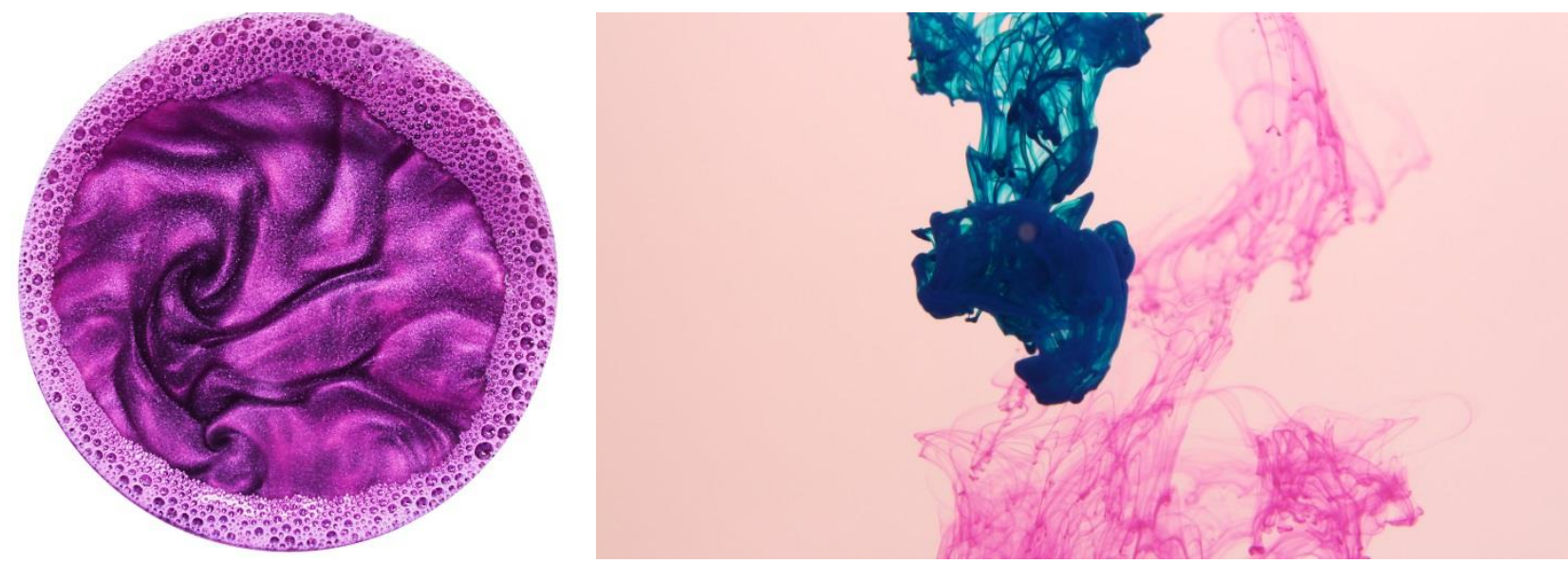

Fig. 6. Assignment 6: heat convection

Students were expected to provide their own cameras (in lieu of a textbook). The camera should provide the option of manual focusing and some type of exposure control: shutter speed, aperture, ISO and preferably all three. Photography professor made many recommendations to students in this regard to help students with purchasing appropriate cameras. Moreover, as a part of the seed grant, five Nikon D3400 DSLR Cameras with AF-P DX NIKKOR 18-55mm F/3.55.6G VR Lens were purchased for this course, so students can check out from library based on first come first serve. Adobe Photoshop and Bridge were recommended for downloading and editing images, and were available to all students for free. Flow Visualization Techniques and Examples book by A. J. Smits and T. T. Lim was recommended as a reference textbook to engineering students. 


\section{Assessments}

There were 6 bi-weekly assignments, 2 course projects, 2 quizzes, and couple in-class activities considered for this course. Students' grade for their assignments was largely determined by the quality of their images, science statements, visualization techniques, and participation in critiques using the rubrics. Qualitative feedback was provided publicly during class critique sessions, by their peers and the instructor.

\section{A. Bi - Weekly Assignments (15 points each)}

For each assignment, students submitted minimum 30 images and chose their top two images (original and retouched versions, total of 4) and uploaded on OneDrive. The assignment report including the link to the OneDrive folder was submitted on Canvas by 11:59pm on Wednesday, every other week. The assignments included a brief report on the science behind the selected images. The rubric was provided (Fig. 7). Late weekly assignments were not accepted, except for legitimate reasons. Students' assignments were evaluated for three GenEd objectives (stated above) in four categories for each assignment: art, science, visualization technique, and documentation. The first category was graded for whether the intent of the image is realized and whether the image was effective. Science behind each image was evaluated based on provided flow properties and how clearly a flow phenomenon is illustrated. The criteria for good photographic techniques are proper exposure, focus, resolution, and presentation as well as the flow visualization technique. The accompanying report was to describe the intent, the phenomenon, and the photographic technique and was evaluated for content and clarity. All students are expected to provide written reports and self-assessments with their images, and report formats are posted on the course Canvas page. On the critique day, students were prepared to speak about their photograph and how it relates to the weekly assignment. 


\begin{tabular}{|c|c|c|c|c|c|c|}
\hline Criteria & \multicolumn{5}{|c|}{ Ratings } & Pts \\
\hline $\begin{array}{l}\text { Elements of } \\
\text { assignment } \\
\text { Required number of } \\
\text { images } \\
\text { photographed, } \\
\text { required number of } \\
\text { original + retouched } \\
\text { images }\end{array}$ & $\begin{array}{l}1.0 \text { pts } \\
\text { Achievement Level } 3 \text { - } \\
\text { All elements submitted }\end{array}$ & \multicolumn{2}{|c|}{$\begin{array}{l}0.5 \text { pts } \\
\text { Achievement Level } 2 \text { - } \\
\text { Missing } 1 \text { element of assignment }\end{array}$} & \multicolumn{2}{|c|}{$\begin{array}{l}0.0 \text { pts } \\
\text { Achievement Level } 1 \text { - } \\
\text { Missing } 2 \text { or more elements of assignment }\end{array}$} & 1.0 pts \\
\hline $\begin{array}{l}\text { Weekly Assignment - } \\
\text { Original Top Image } 1 \\
\text { Include Aperture, } \\
\text { Shutter, ISO, White } \\
\text { Balance, and Date. }\end{array}$ & \multicolumn{2}{|c|}{$\begin{array}{l}2.5 \text { pts } \\
\text { Achievement Level } 4 \text { - } \\
\text { Weekly lesson is visible in work - } \\
\text { understanding of assignment is clear } \\
\text { - photos reflect correct composition } \\
\text { and follows weekly guidelines - } \\
\text { interesting subject matter }\end{array}$} & $\begin{array}{l}2.0 \text { pts } \\
\text { Achievement Level } \\
3 \text { - } \\
\text { Weekly lesson is } \\
\text { somewhat visible in } \\
\text { work - improvement } \\
\text { in subject matter } \\
\text { and composition }\end{array}$ & $\begin{array}{l}1.5 \text { pts } \\
\text { Achievement Level } 2 \text { - } \\
\text { Weekly lesson is } \\
\text { displayed minimally in } \\
\text { work - work needs great } \\
\text { improvement in subject } \\
\text { matter and composition }\end{array}$ & $\begin{array}{l}0.0 \text { pts } \\
\text { Achievement } \\
\text { Level } 1 \text { - } \\
\text { Weekly } \\
\text { lesson is not } \\
\text { visible in } \\
\text { work. }\end{array}$ & $2.5 \mathrm{pts}$ \\
\hline $\begin{array}{l}\text { Weekly Assignment - } \\
\text { Original Top Image } 2 \\
\text { Include Aperture, } \\
\text { Shutter, ISO, White } \\
\text { Balance, and Date. }\end{array}$ & \multicolumn{2}{|c|}{$\begin{array}{l}2.5 \text { pts } \\
\text { Achievement Level } 4 \text { - } \\
\text { Weekly lesson is visible in work - } \\
\text { understanding of assignment is clear } \\
\text { - photos reflect correct composition } \\
\text { and follows weekly guidelines - } \\
\text { interesting subject matter }\end{array}$} & $\begin{array}{l}2.0 \text { pts } \\
\text { Achievement Level } \\
3 \text { - } \\
\text { Weekly lesson is } \\
\text { somewhat visible in } \\
\text { work - improvement } \\
\text { in subject matter } \\
\text { and composition }\end{array}$ & $\begin{array}{l}1.5 \text { pts } \\
\text { Achievement Level } 2 \text { - } \\
\text { Weekly lesson is } \\
\text { displayed minimally in } \\
\text { work - work needs great } \\
\text { improvement in subject } \\
\text { matter and composition }\end{array}$ & $\begin{array}{l}0.0 \text { pts } \\
\text { Achievement } \\
\text { Level } 1 \text { - } \\
\text { Weekly } \\
\text { lesson is not } \\
\text { visible in } \\
\text { work. }\end{array}$ & $2.5 \mathrm{pts}$ \\
\hline
\end{tabular}

Fig. 7. Rubric for grading assignments provided to students on Canvas (continued next page) 


\begin{tabular}{|c|c|c|c|c|c|c|c|c|c|}
\hline \multirow{2}{*}{$\begin{array}{l}\text { Creativity } \\
\text { Retouched } \\
\text { photos/Use of } \\
\text { Photoshop tools }\end{array}$} & \multicolumn{3}{|c|}{$\begin{array}{l}1.0 \text { pts } \\
\text { Achievement Level } 3 \text { - } \\
\text { Work displays a strong sense of creativity and } \\
\text { effort throughout each image. }\end{array}$} & \multicolumn{3}{|c|}{$\begin{array}{l}0.5 \text { pts } \\
\text { Achievement Level } 2 \text { - } \\
\text { Some effort and } \\
\text { creativity is displayed. }\end{array}$} & \multicolumn{2}{|c|}{$\begin{array}{l}0.0 \text { pts } \\
\text { Achievement Level } 1 \text { - } \\
\text { Minimal effort and } \\
\text { creativity is displayed. }\end{array}$} & \multirow{2}{*}{$1.0 \mathrm{pts}$} \\
\hline & $\begin{array}{l}1.5 \text { pts } \\
\text { Achievement Level } \\
4 \text { - } \\
\text { All tools required } \\
\text { were used - } \\
\text { retouch enhances } \\
\text { the image. }\end{array}$ & \multicolumn{3}{|c|}{$\begin{array}{l}1.0 \text { pts } \\
\text { Achievement Level } 3 \text { - } \\
\text { Average amount retouching/use of } \\
\text { tools - retouch enhances the image, } \\
\text { but could still use improvement }\end{array}$} & \multicolumn{3}{|c|}{$\begin{array}{l}0.5 \text { pts } \\
\text { Achievement Level } 2 \text { - } \\
\text { Minimal amount of } \\
\text { retouching/use of tools - } \\
\text { retouch does not enhance } \\
\text { the image. }\end{array}$} & $\begin{array}{l}0.0 \text { pts } \\
\text { Achievement } \\
\text { Level } 1 \text { - } \\
\text { Tools were } \\
\text { not used/No } \\
\text { retouch } \\
\text { present }\end{array}$ & \\
\hline $\begin{array}{l}\text { Critique (must be } \\
\text { present in class to } \\
\text { receive points) }\end{array}$ & \multicolumn{2}{|c|}{$\begin{array}{l}1.5 \text { pts } \\
\text { Achievement Level } 4 \text { - } \\
\text { Student can clearly critique his own } \\
\text { work and explain thought process } \\
\text { and science behind photos - actively } \\
\text { participates in critiquing others } \\
\text { work. }\end{array}$} & \multicolumn{3}{|c|}{$\begin{array}{l}1.0 \text { pts } \\
\text { Achievement Level } 3 \text { - } \\
\text { Student has basic } \\
\text { understanding over } \\
\text { his/her work - some } \\
\text { participation in } \\
\text { critiquing others work }\end{array}$} & \multicolumn{2}{|c|}{$\begin{array}{l}0.5 \text { pts } \\
\text { Achievement Level } 2 \text { - } \\
\text { Student finds it } \\
\text { difficult to interpret } \\
\text { the meaning of the } \\
\text { work - minimal } \\
\text { involvement in critique }\end{array}$} & $\begin{array}{l}0.0 \text { pts } \\
\text { Achievement } \\
\text { Level } 1 \text { - } \\
\text { No } \\
\text { involvement } \\
\text { in critique } \\
\text { and critique } \\
\text { of others. }\end{array}$ & $1.5 \mathrm{pts}$ \\
\hline $\begin{array}{l}\text { Describes Fluid } \\
\text { Phenomena (Writing) }\end{array}$ & \multicolumn{2}{|c|}{$\begin{array}{l}1.0 \text { pts } \\
\text { Achievement Level } 3 \text { - } \\
\text { Clearly written Information is } \\
\text { organized Good spelling and } \\
\text { grammar Professional language } \\
\text { (publishable) }\end{array}$} & \multicolumn{5}{|c|}{$\begin{array}{l}0.5 \text { pts } \\
\text { Achievement Level } 2 \text { - } \\
\text { Writing is somewhat clear Information is } \\
\text { somewhat organized Few spelling and grammar } \\
\text { mistakes Common language (not publishable) }\end{array}$} & $\begin{array}{l}0.0 \text { pts } \\
\text { Achievement } \\
\text { Level } 1 \text { - } \\
\text { Writing does } \\
\text { not meet the } \\
\text { requirements }\end{array}$ & $1.0 \mathrm{pts}$ \\
\hline $\begin{array}{l}\text { Provides information } \\
\text { needed for } \\
\text { reproducing flow }\end{array}$ & \multicolumn{3}{|c|}{$\begin{array}{l}1.5 \text { pts } \\
\text { Achievement Level } 3 \text { - } \\
\text { Fluid properties, flow rates, and geometry } \\
\text { information are provided }\end{array}$} & \multicolumn{3}{|c|}{$\begin{array}{l}1.0 \text { pts } \\
\text { Achievement Level } 2 \text { - } \\
1 \text { or } 2 \text { fluid information } \\
\text { is missing }\end{array}$} & \multicolumn{2}{|c|}{$\begin{array}{l}0.0 \text { pts } \\
\text { Achievement Level } 1 \text { - } \\
\text { More than } 2 \text { fluid } \\
\text { information is missing }\end{array}$} & $1.5 \mathrm{pts}$ \\
\hline $\begin{array}{l}\text { Provides information } \\
\text { needed for } \\
\text { reproducing flow } \\
\text { visualization } \\
\text { technique }\end{array}$ & \multicolumn{3}{|c|}{$\begin{array}{l}1.5 \text { pts } \\
\text { Achievement Level } 3 \text { - } \\
\text { Method, dilution, injection speed, settings, } \\
\text { and lighting source are provided }\end{array}$} & \multicolumn{3}{|c|}{$\begin{array}{l}1.0 \text { pts } \\
\text { Achievement Level } 2 \text { - } \\
1 \text { or } 2 \text { flow visualization } \\
\text { information is missing }\end{array}$} & \multicolumn{2}{|c|}{$\begin{array}{l}0.0 \text { pts } \\
\text { Achievement Level } 1 \text { - } \\
\text { More than } 2 \text { flow visualization } \\
\text { information is missing }\end{array}$} & $1.5 \mathrm{pts}$ \\
\hline $\begin{array}{l}\text { Describe the physics } \\
\text { of fluid }\end{array}$ & \multicolumn{2}{|c|}{$\begin{array}{l}1.0 \text { pts } \\
\text { Achievement Level } 3 \text { - } \\
\text { Clearly explains phenomena, Flow } \\
\text { is understandable, Physics } \\
\text { revealed, Creative flow or } \\
\text { technique }\end{array}$} & \multicolumn{5}{|c|}{$\begin{array}{l}0.5 \text { pts } \\
\text { Achievement Level } 2 \text { - } \\
\text { Phenomena is somewhat explained, Flow is } \\
\text { somewhat understandable, Physics is somewhat } \\
\text { revealed, Some effort and creativity is displayed }\end{array}$} & $\begin{array}{l}0.0 \text { pts } \\
\text { Achievement } \\
\text { Level } 1 \text { - } \\
\text { Minimal } \\
\text { effort is } \\
\text { displayed }\end{array}$ & $1.0 \mathrm{pts}$ \\
\hline
\end{tabular}

Total Points: 15.0

Fig. 7. Rubric for grading assignments provided to students on Canvas 


\section{B. In-Class Critical Analysis (ICCA) (2 points each)}

The in-class critical analysis activities included analyzing famous images related to flow visualization (both artistic and/or scientific). A text Dropbox was open for 15 minutes at the beginning of some classes and students were required to critically analyze a photograph by writing 3-4 sentences. They were asked to answer these specific questions: What does this photograph show? Why did the photographer take it? Is it Artistic or Scientific? There were no make-up dates for these short assignments.

\section{Quizzes (20 points each)}

Two announced quizzes were given over the semester. The format was primarily short answer and multiple choices. Quizzes included, but not limited to, definitions, image description, Photoshop tools, fluid properties, physics of flow, and flow visualization techniques.

\section{Mini Project (30 points)}

The mini project's intention was to challenge students on capturing a crown splash of a liquid (e.g. milk, water, etc.). Before Harold Edgerton rigged a milk dropper next to a timer and a camera of his own invention, it was virtually impossible to take a good photo in the dark without bulky equipment. The electrical-engineering professor at MIT combined high-tech strobe lights with camera shutter motors to capture moments imperceptible to the naked eye. "Milk Drop Coronet, his revolutionary stop-motion photograph, freezes the impact of a drop of milk on a table, a crown of liquid discernible to the camera for only a millisecond. The picture proved that photography could advance human understanding of the physical world, and the technology Edgerton used to take it laid the foundation for the modern electronic flash." [11] This was a challenging task for all students to understand timing, lighting, and physics of drops to capture a focused image. Appropriate instructions were provided on how to shoot water drop. [12]
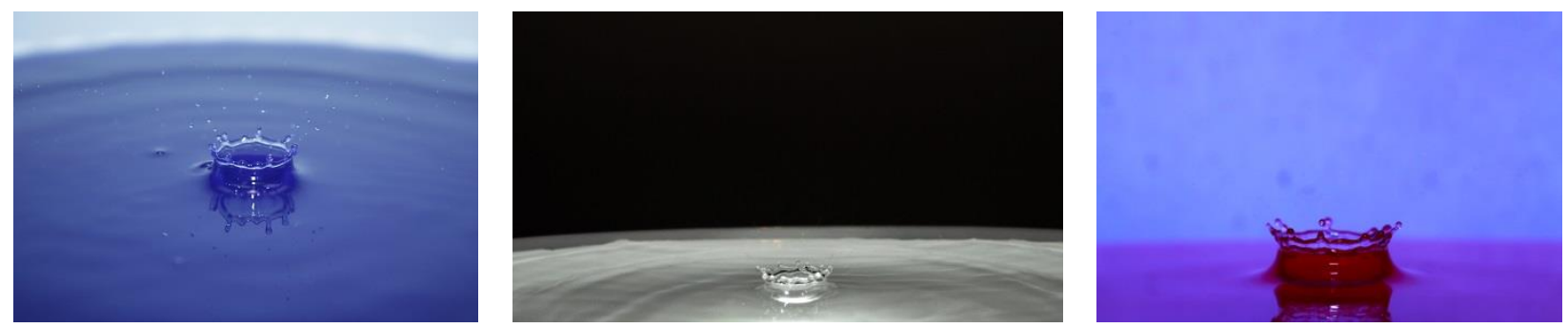

Fig. 8. Mini Project: Crown Challenge

\section{E. Final Project (80 points)}

For the final project, students could choose any topic related to the course materials and asked to consult with their professors for their approval. Students were in groups of maximum two to image complex flow phenomena and attempt more challenging imaging techniques for their projects. All students were expected to do in-depth research on their topic and provide written scientific reports with their artistic images. Some of students' images can be seen in Fig. 9. One sample student project report (Fig. 9c) is included in Appendix A to better establish the 
significance of the final project and the link to the engineering and scientific concepts. In addition, at the end of the semester, a public gallery of the students' work was held on campus. Students were asked to explain their pictures to students and faculty from other disciplines, as well as public audiences. Students had two-day professional training on public speaking and poster presentation by a faculty in Communication Department. Outside judges graded students' presentation. A selection of images from the course will be available on a public website.

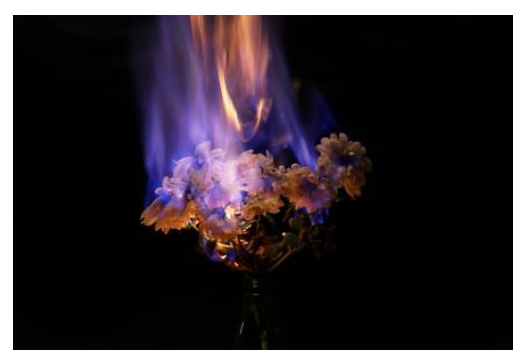

(a)

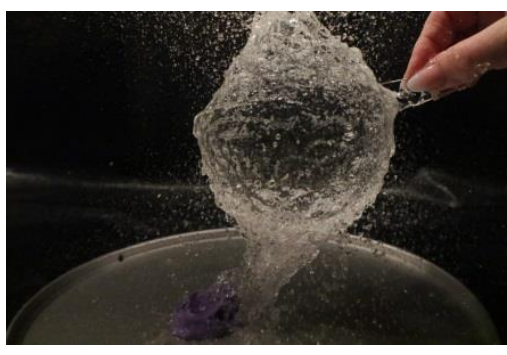

(b)

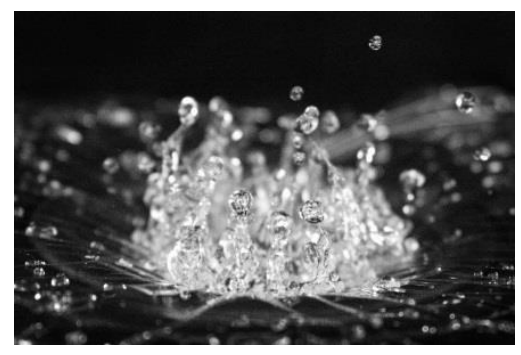

(c)

Fig. 9. Sample Final Projects: a) burning mums, b) water balloon, c) dancing drops.

\section{F. Art/Science Competition Entry (Extra 10 points)}

Students were encouraged to submit their work to art/science competitions for extra credits. Students were asked to submit their intention at the beginning of semester and only one student submitted his work to the Gallery of Fluid Motion, which has been sponsored by the Division of Fluid Dynamics of the American Physical Society, since 1985.

\section{Outcomes}

Since the course is taught only one time, the evaluation of learning objectives is very qualitative. Some survey results show that students enjoyed the class time and the combination of science and photography. Some suggestions on how to improve the course are provided. When students were asked "What do you like about PHOTO $321 \mathrm{~N}$ course?", they mostly answered that this course helped them to be creative and look at things from a different perspective. When students were asked "Let us know if you think you are meeting course expectations in terms of "Integrative Thinking" learning objective in both Arts and Natural Sciences domains", all of students felt they are meeting the course expectations.

There were two engineering students who had already taken Fluid Mechanics, and they mentioned how this course helped them to effectively cover the physics of fluid flow, using Flow Visualization as a powerful tool. It is noteworthy that the topics covered in this course were carefully selected to not overlap with the engineering courses. In the case of students who were not familiar with fluids, the course enlightened them, but in the case of someone who knew a little about the underlying mechanics, it showed even more. This shows that something like this 
course is a good example of useful cross-disciplinary coursework and can be an effective method of education and reach people at all different levels at the same time.

When students were asked about the "effective communication" skills during their final project poster presentation, the result was remarkable. $95 \%$ of students said it significantly helped them with initiating the conversation and engaging the audience. For $63 \%$ of students, handling Q \& A during their poster session and for $74 \%$ of them, managing communication confidence was achieved. $26 \%$ of students mentioned that they learned how to create a poster and organize their poster layout. When students were asked "If you were an instructor, what would you change in PHOTO 321N course to improve the students learning?", one main suggestion was to give short quizzes after each topic to give the lectures more substance to the course.

\section{Conclusions}

The results from this experimental course illustrated very clearly that Flow Visualization can be performed successfully by students from a wide range of background. Despite the disparate backgrounds of the students enrolled in the course, no general differences in either the scientific or artistic quality of their images or any pattern that relates their work to their major could be detected. Everyone is capable of making beautiful images and explaining accurate observations of interesting fluid phenomena with appropriate training. Many of the students had no previous experience with the flows they generated or photography. Many of the flows investigated required little fluid flow apparatus as such, and only basic photographic equipment. The Flow Visualization class showed significantly more positive attitude shifts than regular science and art classes. The authors are hoping to spread the words among their peers at ASEE conference and encourage more educators to teach such courses. Future work will include studies of whether this course creates visual expertise, and a new image-based survey to investigate students' perceptions of aesthetic vs. utilitarian representations. Determining which elements cause students in Flow Visualization course to have positive attitude will allow for incorporation of those elements into other engineering classes to improve learning objectives and student engagement.

\section{References}

[1] Hertzberg, J., Sweetman, A., "A Course in Flow Visualization: The Art and Physics of Fluid Flow," Proceedings of American Society for Engineering Education Annual Conference and Exposition, 2004.

[2] Hertzberg, J., "Seeing Fluid Physics: Outcomes From a Course on Flow Visualization," Bulletin of the American Physical Society, Paper \# QE3, 55 (16), 2010.

[3] Poon, M., Todd, J., Neilson, R., Grace, D., Hertzberg, J., "Saffman-Taylor Instability in a Hele-Shaw Cell," Physics of Fluids, 16 (9), p. S9, 2004.

[4] Settles, G. S., "On the Fluid Dynamicist as Artist," Proceedings of the 12th International Symposium on Flow Visualization, Gottingen, Germany, 2006. 
[5] Kleine, H., Settles, G. S., "The Art of Shock Waves and Their Flow Fields," Shock Waves, 17, pp. 291-307, 2008.

[6] Samuel, M., Henley, J., and Shakerin, S., "Development of a Wet Wall: An Undergraduate Research Project," Paper \#37677, Proceedings of the 5th ASME/JSME Joint Fluids Engineering Conference, San Diego, CA, 2007.

[7] Shakerin, S., "Micro-controlled Water Fountain: A Multidisciplinary Project," International Journal of Engineering Education, 20 (4), pp. 654-659, 2004.

[8] Shakerin, S., "Water Fountains with Special Effects," American Scientist, 93 (5), pp. $444-$ 451, 2005.

[9] Robinson, C., and Baxter, S., "Turning STEM into STEAM", Proceedings of American Society for Engineering Education Annual Conference and Exposition, 2013.

[10] Hertzberg, J., A course in the physics and art of fluid flow: http://www.flowvis.org/

[11] TIME, 100 Photo Collection, http://100photos.time.com/photos/harold-edgerton-milk-drop

[12] First Man Photography, https://www.firstmanphotography.com/photographytutorials/tutorials/water-drop-photography 


\title{
Appendix A: Sample Final Project Report Final Project - Dancing Drops
}

\author{
Report
}

First Name and Last Name: and

Email Address:

Date:

OneDrive Link for this assignment folder including minimum 30 images, top 2 original images, and top two edited images:

\section{Introduction}

Most people on this planet have probably experienced the motion of a fluid everyday of their life so far, whether that be drinking a glass of water, breathing in air, or listening to the crash of ocean waves on a beach. Most of them however probably don't notice the unique properties that these fluids have and how they interact with the natural world around us. We call this "Flow phenomena", and we use it to describe the movement of the solids, liquids and gases we encounter in our everyday lives. When we conducted our final project, there was one main goal we had in mind; to bring together the beautiful complexity of both art and science into one harmonious image. To begin our experiment, we wanted to capture the effects of sound waves on liquid water, so we chose to use a subwoofer to be our source of sound so we could easily adjust its frequency to get a range of motion from the water. We then put different liquids on top of the speaker starting with water and observed the effect that varying frequencies had on the fluids. There are many properties of fluids such as density and viscosity which are factors that will dictate the motion they will undergo when impacted by an outside source, such as a sound wave. By understanding their properties, we can predict how they will act in nature when they undergo motion, as well as create an image of art that reflects all of the science that goes on to create this motion.

\section{Physics of Fluid Motion}

A puddle of water rests gently upon a 9-inch-wide subwoofer connected to an auxiliary amplifier playing heavy bass music at 16 Kilo Hertz. When there is an increase in amplitude frequency, the density of the number of water droplets increases, while a decrease in sound wave frequency causes a decrease in water droplet density. In other words, the softer the music is, the water molecules will resonate rather than separate, or move closer apart without completely separating. The louder the sound is 
however, the more the water molecules will separate and chaotically "splash" upward and outward in the form of droplets. This phenomenon can be explained using the Theory of Harmonic Distortion and Spherical Waves which states that sound wave frequency distorts fluid while conserving the fluid's initial mass. This theory discovered in 1965 by Oliver $\mathrm{H}$. McDaniel uses the following equation to describe the continuity of an expanding fluid: $\mathrm{vp}-\mathrm{Po}=\mathrm{As}+(\mathrm{B} / 2$ !) $) \mathrm{s} 2 \mathrm{t}$ [1]. This equation is derived from the fundamental equation of motion in general physics, $\mathrm{F}=\mathrm{ma}$ and relates the variables of sound wave velocity, amplitude, entropy and time, to calculate the energy loss in an expanding fluid. Once the sound waves are amplified by an exterior source, the water puddle turns into a chaotic splash of droplets that spew in every direction due to the lower frequency of the sound waves being produced by the woofer. Traditionally water creates symmetrical ripples when disrupted by a centralized force from an impact object, but in the case of sound wave penetration, the ripples form a bubble shape because of the 3 dimensionality of sound waves and its force being exerted upon the water from all angles, thus creating a "dancing" effect. Another interesting thing about the science of this experiment, is the fact that most of the time when water makes a splash, it is being impacted by an object with a downward force, such as a person jumping into a swimming pool. However, in our experiment the force that enacted upon the fluid was one with an upward force, since the sound waves were pointing upward towards the water puddle, and the vertical columns were created in the image because the water essentially fell back on itself continuously, being the object performing the splashing and receiving the splashing. In a study done by G. J. Franz in 1959, time intervals were measured between the formation of water columns as result of water splashing back into water, down to millisecond intervals. What he found is that the entire process of the water forming a column and splashing back onto itself occurs within a time interval of 70 220 milliseconds [2]. This study allowed us to understand the changes that the fluid had undergone at certain intervals of time, and what time period the columns formed. While taking this picture we encountered many challenges however, such as the splashing of the water onto the camera lens and getting the right focus of the water drops just to name a few. We overcame these challenges by adjusting our camera zoom while using a pen to focus in on the entirety of the image. While conducting our experiment we also used Oobleck and milk to see how the sound waves would affect different liquids with different properties. The first liquid we tested was whole milk at room temperature. The milk performed similarly to the water in that it created vertical columns but had a bit more long lasting structure due to its slightly greater density. When we tested the Oobleck however, the molecules had a very hard time separating due to its very high density and solid like properties and took a much greater amount of energy from the sound waves to even move the Oobleck at all. We then tried ketchup it was hardly disturbed due to its high viscosity and also due to it being a non-Newtonian fluid.

\section{Flow Visualization}

To capture and recreate our image, we used the following materials in the list below.

- Canon Eos rebel sl 1 camera

- Nikon D3400 camera

- Adjustable tripod

- Camera flash (optional based on lighting)

- 2 stereo speakers/subwoofers connected to amplifier 
- Amplifier

- Audio source (smart phone)

- Aux cable to connect audio source to amplifier

- Clear Saran Wrap to protect speakers

- Well-lit open room

- Water (room temperature)

- Milk (whole, room temperature)

- Oobleck (2 cups of cornstarch 1 cup water, room temperature)

- Tomato Ketchup (room temperature)

- Food coloring (various colors for different effects)

- Black fabric for a background

- Level box to put speaker on top of

The flow visualization technique was simple in our project. We decided to just observe the raw state of the fluids with some minor adjustments to them such as type of fluid and the addition of color dye into the Oobleck and Milk to make it easier and more fun to visualize. We measured the air temperature of the garage to be approximately 24 degrees Celsius and the humidity to be $43 \%$ which are about average room temperatures. The lighting of the garage was lit by the outside sun coming into the garage at about 12 PM in the afternoon. Initially we used a flash to try and see if it would improve the lighting, but we decided it just made the image too bright and took away some of the clarity and natural feel and was not necessary overall. We then used adjustable LED lights hooked up on either side of the speaker too add more lighting from the angels that we needed it from and were able to capture the image we have shown below. Our complete setup is also shown in the experimental image section below.

\section{Photography Technique}

First, we chose to present more of a close-up shot. We felt that this portrayed the flow visualization with more detail. We ended up having to add black space around the edge in order to give the text more of a place on the poster, but because the shot was close-up, we were able to keep the detail. We also made sure to have the field of view wide enough so that we could get rid of it, replacing it with a black background. The focal length of the lens is $18-55 \mathrm{~mm}(\mathrm{f} 3.5-5.6)$, however we had it at $55 \mathrm{~mm}$ when we took this picture. This picture was taken on a Nikon D3400, digital camera. The photo was taken with aperture of f5.6, shutter speed 1/2000, ISO 25600, and AWB. For the Photoshop tools, Dodge and burn, hue and saturation, crop, clarity, sharpening, noise reduction, levels, raw filter, and luminance were used. I also created a black canvas to enhance the black space around the picture. We made sure to keep the shutter speed as high as possible in order to capture the moving water droplets in focus. This caused for a higher than desired ISO, and a low aperture.

\section{Art of Fluid Motion}

The images that we took reveal that science and art can come together into one image. This was something that we were proud to capture because we believe it is important to show that science can be fun and exciting and is something that everyone can enjoy. There is a lot that goes on behind the 
motion of fluid and we tried to bring that to a level of comprehension so that everyone can not only enjoy the picture, but really bring it to life and communicate what is going on within it. We believe a creative aspect of this project was not only using sound waves to distort fluid, but also our pursuit to try different types of fluids other than water such as Oobleck, milk and ketchup and explore and understand their different properties. The addition of different colors into these liquids also made them that much more interesting and fun to look at shown in our videos of their motion and helps make otherwise dull substances into a dancing concert of craziness! Perhaps the thing we like the most about the image is how tranquil and calming it is to look at but also how it can be perceived to be droplets that are dancing to music. We believe that the fluid of the physics is shown in our image because the formation of columns and splashing droplets are the result of a higher sound wave frequency which is described by the harmonic distortion equation which is derived from the $\mathrm{F}=$ ma equation in physics. Oobleck acts more like a solid when it is still but more like a liquid when it is in motion. Some questions we have is how Oobleck maintains its shape and doesn't separate easily while it is undergoing high frequencies even though it seems to have more liquid like properties when it is in motion. We also wondered why milk, even though it has a very similar density to water, maintained its vertical column structure as it was undergoing higher frequencies. However, we were able to express our intent of bringing art to science by connecting the beauty of natural water to the effect that sound waves as certain frequencies have on its motion ultimately creating unique flow phenomena. Perhaps one aspect that we would like to improve is the focus and clarity to capture the very best image possible, and perhaps this could be achieved by having natural lighting from outside and lowering the view field. An interesting direction that we could go in progressing this idea, would be testing out different size speaker platforms and understanding how a larger surface area of sound waves would affect the fluid motion and what would stay the same and what would be different.

\section{References}

[1] McDaniel, Oliver H. "Harmonic Distortion of Spherical Sound Waves in Water." The Journal of the Acoustical Society of America. The Pennsylvania State University: University Park, Pennsylvania. 1965.

[2] G. J. Franz, "Splashes as Sources of Sounds in Liquids" The Journal of the Acoustical Society of America. David Taylor Model Basin, Washington, D.C. 1959. 
Image \#1 should be your final project top image!

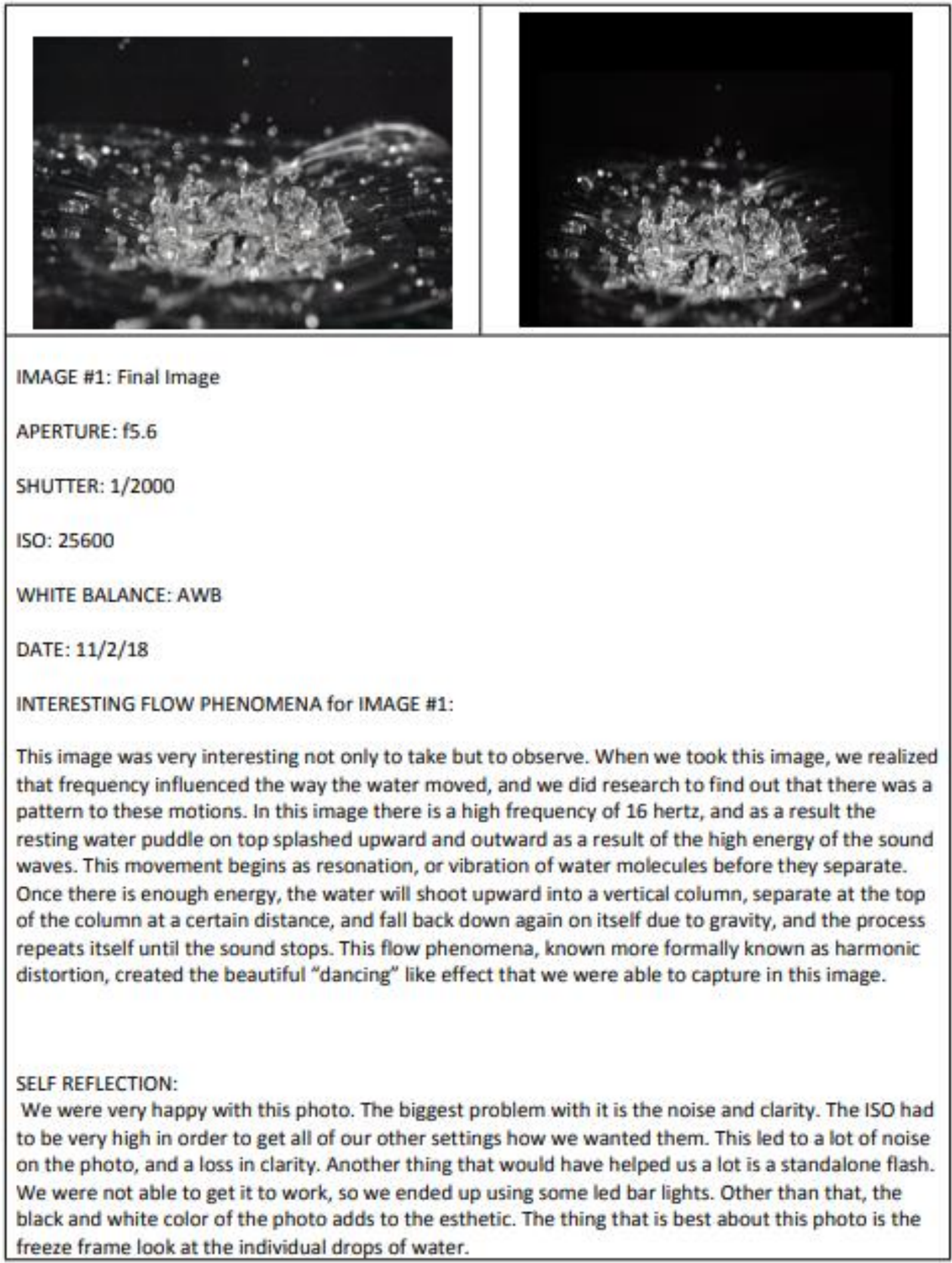


Image \#2 should be your final project experimental setup image!

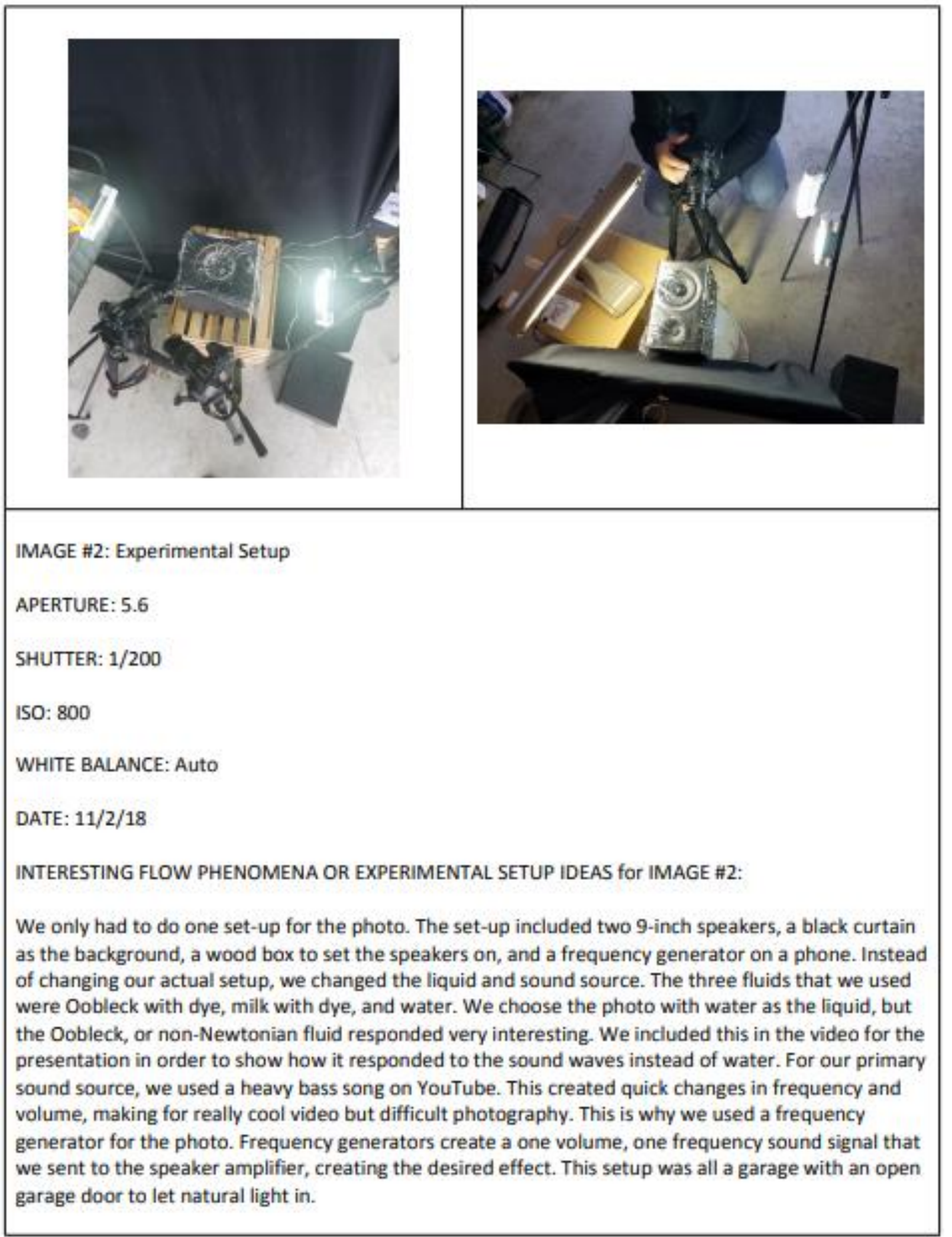

